\title{
Simulations of the Performance of Maximum Power Point Tracking Algorithms Based on Experimental Data According to the Topologies of DC-DC Converters
}

\author{
Abraham Dandoussou ${ }^{1}$, Pierre Kenfack ${ }^{1}$, Stève Ngoffe Perabi ${ }^{2}$, Martin Kamta ${ }^{3}$ \\ ${ }^{1}$ University of Buea, Department of Electrical and Power Engineering, Higher Technical Teachers' Training College (HTTTC), \\ Kumba, Cameroon \\ ${ }^{2}$ University of Douala, Department of Electrical Engineering and Industrial Computing, Institut Universitaire de Technologie, \\ Douala, Cameroon \\ ${ }^{3}$ University of Ngaoundere, Department of Electrical Engineering, Energetic and Automation, National School of Agro-Industrial \\ Sciences, Ngaoundere, Cameroon \\ Email: Abraham.dandoussou@ubuea.cm,pierrekenfack2003@yahoo.fr,ngoffeperabi@yahoo.fr, martin_kamta@yahoo.fr
}

How to cite this paper: Dandoussou, A., Kenfack, P., Perabi, S.N. and Kamta, M. (2021) Simulations of the Performance of Maximum Power Point Tracking Algorithms Based on Experimental Data According to the Topologies of DC-DC Converters. Journal of Power and Energy Engineering, 9, 76-92.

https://doi.org/10.4236/jpee.2021.95005

Received: March 9, 2021

Accepted: May 19, 2021

Published: May 22, 2021

Copyright $\odot 2021$ by author(s) and Scientific Research Publishing Inc. This work is licensed under the Creative Commons Attribution International License (CC BY 4.0).

http://creativecommons.org/licenses/by/4.0/

\section{(c) (i) Open Access}

\begin{abstract}
Maximum Power Point Tracking (MPPT) algorithms are now widely used in PV systems independently of the weather conditions. In function of the application, a DC-DC converter topology is chosen without any previous performance test under normal weather conditions. This paper proposes an experimental evaluation of MPPT algorithms according to DC-DC converters topologies, under normal operation conditions. Four widely used MPPT algorithms i.e. Perturb and Observe ( $\mathrm{P} \& \mathrm{O}$ ), Hill Climbing (HC), Fixed step Increment of Conductance (INCF) and Variable step Increment of Conductance (INCV) are implemented using two topologies of DC-DC converters i.e. buck and boost converters. As input variables to the PV systems, recorded irradiance and temperature, and extracted photovoltaic parameters (ideality factor, series resistance and reverse saturation current) were used. The obtained results show that buck converter has a lot of power losses when controlled by each of the four MPPT algorithms. Meanwhile, boost converter presents a stable output power during the whole day. Once more, the results show that INCV algorithm has the best performance.
\end{abstract}

\section{Keywords}

MPPT Algorithms, DC-DC Converters, Photovoltaic Parameters, Normal Operating Conditions 


\section{Introduction}

Energy extracted from a solar panel depends on weather conditions which bring it to be an intermittent energy source [1] [2] [3]. However, the direct connection of a solar panel to a direct current (DC) load or to an alternating current (AC) load via an inverter becomes weak because the transfer of the maximum power will be difficult when the irradiance changes. The direct connected photovoltaic system is the cheapest and the worldwide one. The operating point of the solar panel depends on the impedance of the load. It is the intersection between the I-V (or P-V) characteristic of the solar panel and that of the load. In order to prevent the reverse flow of the current, a diode is connected between the solar panel and the load. This system does not offer any possibility to limit or to set the voltage at the terminals of the load. Meanwhile, it is not evident to transfer the maximum power to the load [4]-[9]. That is why it is necessary to insert an impedance match block between the load and the photovoltaic (PV) panel. This block can be a DC-DC converter which is controlled by an electronic system in order to follow the maximum power point of the solar panel. The maximum power point tracking (MPPT) command system which can be analogue or digital, changes the duty ratio of the command pulses of the DC-DC converter in order to bring the operating point to the maximum power point when the irradiance is changing. There are various topologies of DC-DC converters:

$\checkmark$ A buck converter with the DC output voltage lower than or equal to the DC input voltage.

$\checkmark$ A boost converter with the DC output voltage greater than or equal to the DC input voltage.

$\checkmark$ A buck-boost converter with the DC output voltage greater than or lower than or equal to the DC input voltage.

Since 1968 with the first MPPT algorithm, many other types of MPPT algorithms have been developed: Perturb and Observe (P \& O), Incremental Conductance (INC), Hill Climbing (HC), Voltage or Current fraction, Fussy logic, Neural network, Ripple correlation control (RCC), etc. [10]-[15]. All these MPPT algorithms are implemented to control a boost converter in a PV system. Preliminary studies are necessary for the choice of a topology of DC-DC converters. Most recent works are only based on a boost converter [16] [17] [18] [19] [20]. This means that the performance of MPPT algorithms is evaluated particularly on this topology mostly used in a PV system. However, it will be necessary to evaluate the performance of MPPT algorithms when another topology of DC-DC converter is used.

This paper evaluates four of the various MPPT algorithms according to the buck and the boost converter, under normal weather conditions. The four MPPT algorithms are: P \& O, HC and INC (fixed step, INCF and variable step, INCV). The main objective is to determine which MPPT algorithm and which DC-DC converter topology are suitable for sub-Saharan (tropical) weather conditions. In the second section, methods used for this work are presented. Then the results are presented and discussed. 


\section{Methods}

\subsection{Experimental System and Material}

In order to collect data for this research work, the system represented in Figure 1(a) was used, with the image shown in Figure 1(b). This system is a direct-connected stand-alone $\mathrm{PV}$ system. The various components are:

$\checkmark$ A pyranometer for the measurement of the global irradiance (in $\mathrm{W} / \mathrm{m}^{2}$ ). Its specifications are given in Table 1.

$\checkmark$ Voltage and current sensors (ALMEMO ${ }^{\circ}$ ) for the measurement of voltage and current respectively.

$\checkmark$ A temperature sensor (ALMEMO ${ }^{\circ}$ ) for the measurement of the temperature at the surface of the solar panel. Its specifications are given in Table 2.

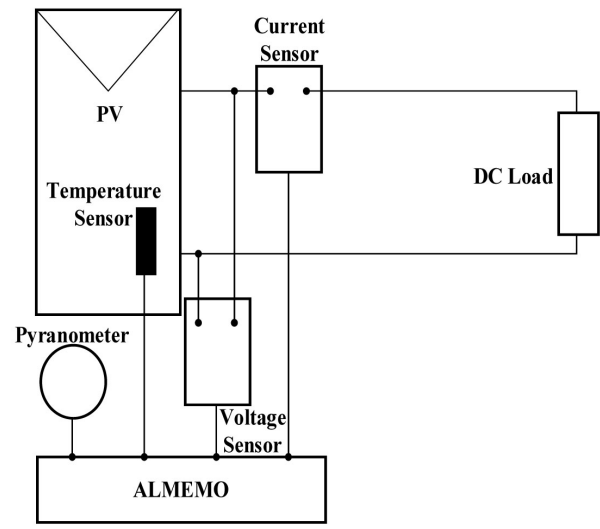

(a)

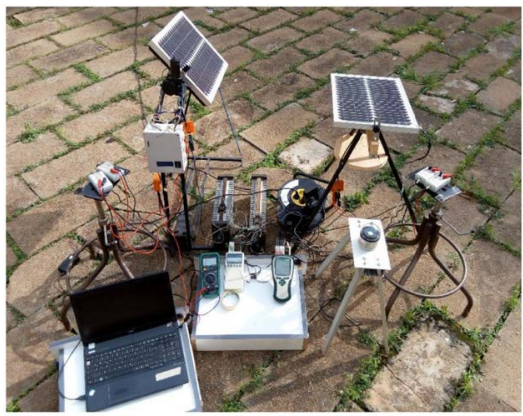

(b)

Figure 1. (a) Block diagram of the experimental system; (b) Image of the outdoor system.

Table 1. Specifications of the pyranometer.

Spectral Range
Sensibility
Impedance
Output Range (0 to $1500 \mathrm{~W} / \mathrm{m}^{2}$ )
Maximum Irradiance
Rising time $(63 \%)$
Rising time $(95 \%)$
Sensor type
Temperature Range

$285-2800 \mathrm{~nm}$

2 - $20 \mu \mathrm{V} / \mathrm{W} / \mathrm{m}^{2}$

$20-200 \Omega$

0 - $30 \mathrm{mV}$

$2000 \mathrm{~W} / \mathrm{m}^{2}$

$<1.2 \mathrm{~s}$

$<5$ s

Thermopile

$-40^{\circ} \mathrm{C}$ to $+80^{\circ} \mathrm{C}$

Table 2. Specifications of the temperature sensor.

\begin{tabular}{cc}
\hline Type & CTN FNA 611 \\
\hline Measurement Range & $-10^{\circ} \mathrm{C}$ to $+90^{\circ} \mathrm{C}$ \\
T90 & $20 \mathrm{~s}$ \\
Cable & $2 \mathrm{~m} \mathrm{PVC}$ \\
\hline
\end{tabular}


An ALMEMO $^{\circ}$ data acquisition unit having five inputs, two outputs, an EEPROM of $1 \mathrm{MB}$ (200,000 measures).

\subsection{Methods}

\section{1) DC-DC converters}

Two topologies of DC-DC converters are used in this work: the buck and the boost converters.

$\checkmark$ The buck converter is represented in Figure 2. Its operating principle is based on the two conduction modes: continuous conduction mode (CCM) and discontinuous conduction mode (DCM). The output voltage and current of the buck converter are given in Equations (1) and (2) respectively.

$$
\begin{gathered}
V_{S}=\alpha V_{p v} \\
I_{S}=\frac{I_{p v}}{\alpha}
\end{gathered}
$$

With $\alpha$ the duty ratio $(0<\alpha \leq 1)$.

$\checkmark$ The boost converter is represented in Figure 3. Its operating principle is also based on the two conduction modes. And its output voltage and current can be obtained as shown in Equations (3) and (4) respectively.

$$
\begin{gathered}
V_{S}=\frac{V_{p v}}{1-\alpha} \\
I_{S}=(1-\alpha) I_{p v}
\end{gathered}
$$

With $\alpha$ the duty ratio $(0<\alpha \leq 1)$.

\section{2) MPPT algorithms}

Many MPPT algorithms have been developed. In this paper, the focus was only on the most popular and the worldwide algorithms: P \& O, HC and INC (fixed and variable steps).

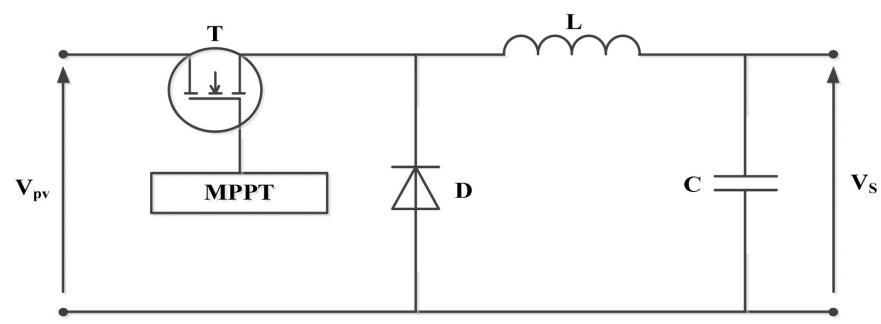

Figure 2. Circuit of a buck converter [21] [22].

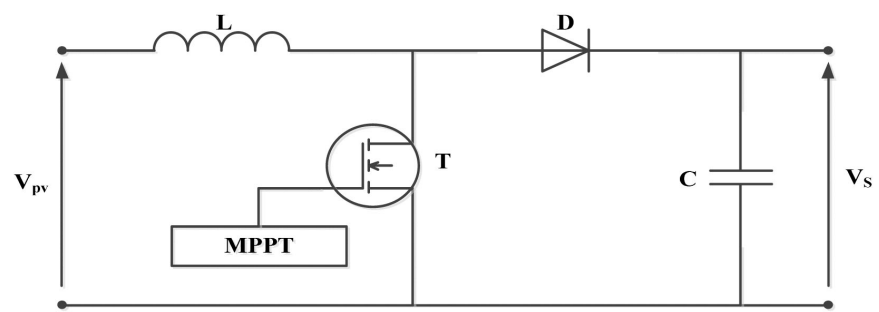

Figure 3. Circuit of a boost converter [21] [22]. 
$\checkmark$ The Hill Climbing algorithm is based on the perturbation of the duty ratio. Its flow chart is represented in Figure 4. The main advantage of this method is that it is easy to implement. However, when the weathers conditions are changing rapidly, this algorithm is no more accurate because of oscillations around the maximum power point [23] [24] [25].

$\checkmark$ The Perturb and Observe (P \& O) algorithm with its flowchart represented in Figure 5 is based on the perturbation of the output voltage of the PV source. This MPPT algorithm is easy to implement and is also the most used nowadays. However, due to the rapidly change of the weather conditions, it becomes inaccurate with an oscillation occurred around the maximum power point [23] [24] [25].

$\checkmark$ The Incremental Conductance (INC) algorithm which is divided into two types: the fixed step one and the variable step one. The fixed step incremental conductance (INCF) algorithm operates like the P \& O algorithm with the same performance. Its flowchart is shown in Figure 6. The variable step incremental conductance (INCV), represented in Figure 7, has been developed in order to solve the problem occurred during the operation of the INCF algorithm. In fact, the INCF algorithm becomes inaccurate when the weather conditions change rapidly, leading energy lost. With a variable step (INCV), there is no more energy lost and the maximum power point is tracked accurately. However, the INCV is difficult to implement. Liu et al. in 2008 developed the first INCF with the variation step $\left(D_{\text {step }}\right)$ given in Equation (5). Coefficient $N$ is determined according the condition given in Equation (6) [23]-[28].

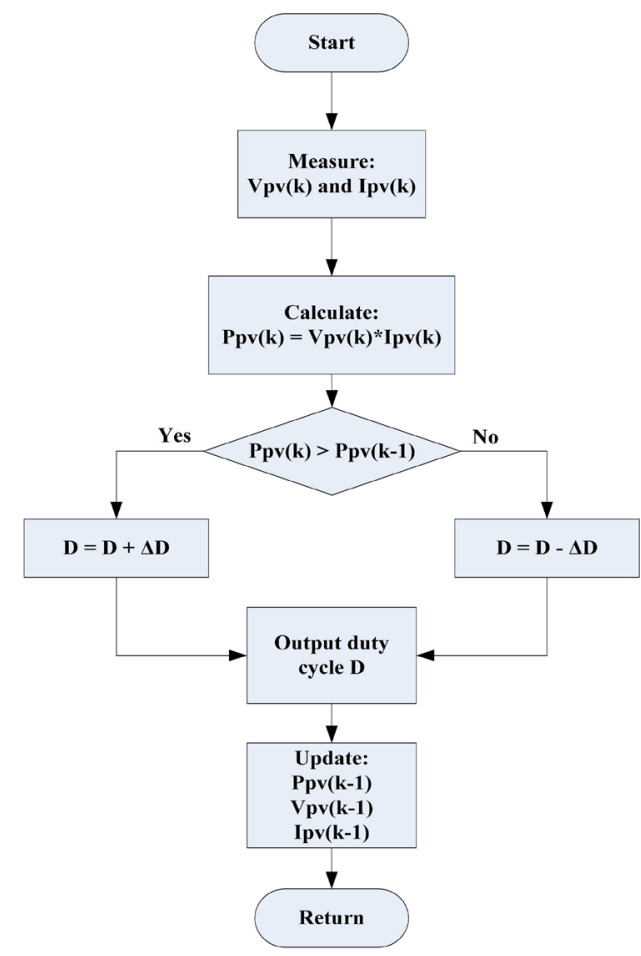

Figure 4. Flowchart of the HC algorithm. 


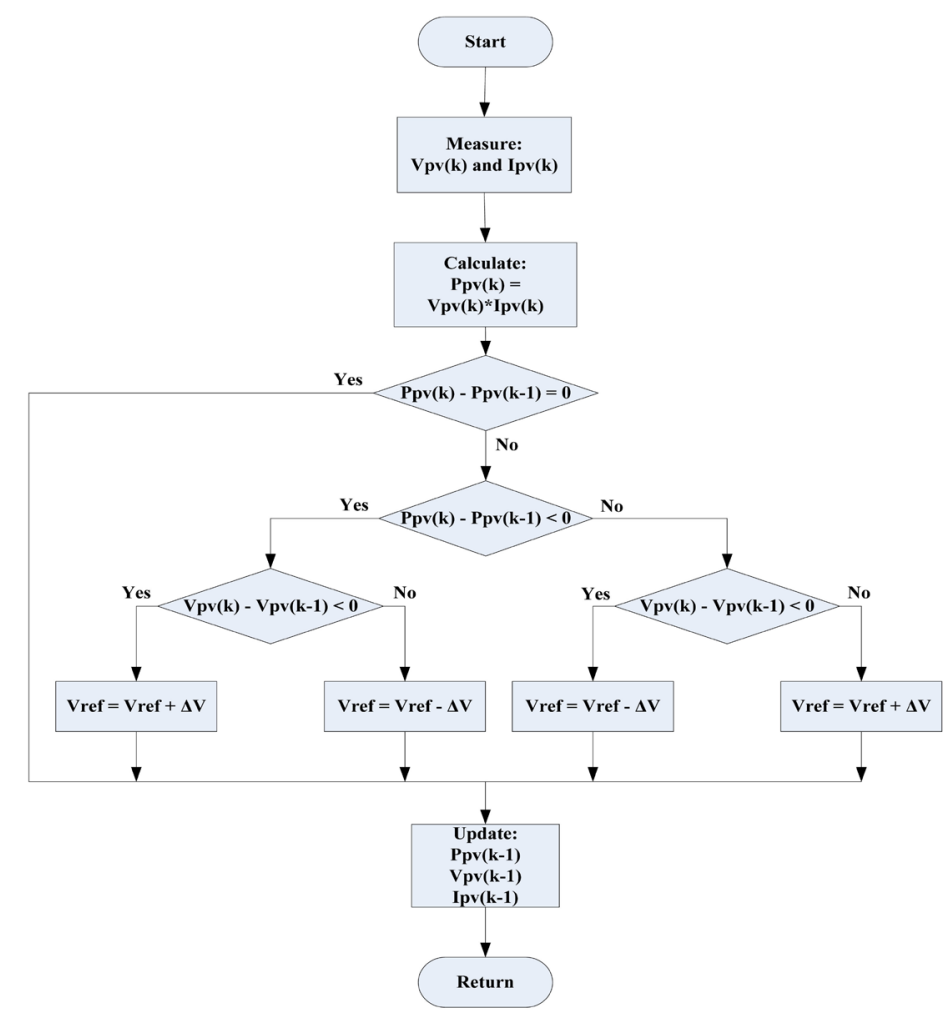

Figure 5. Flowchart of the P \& O algorithm.

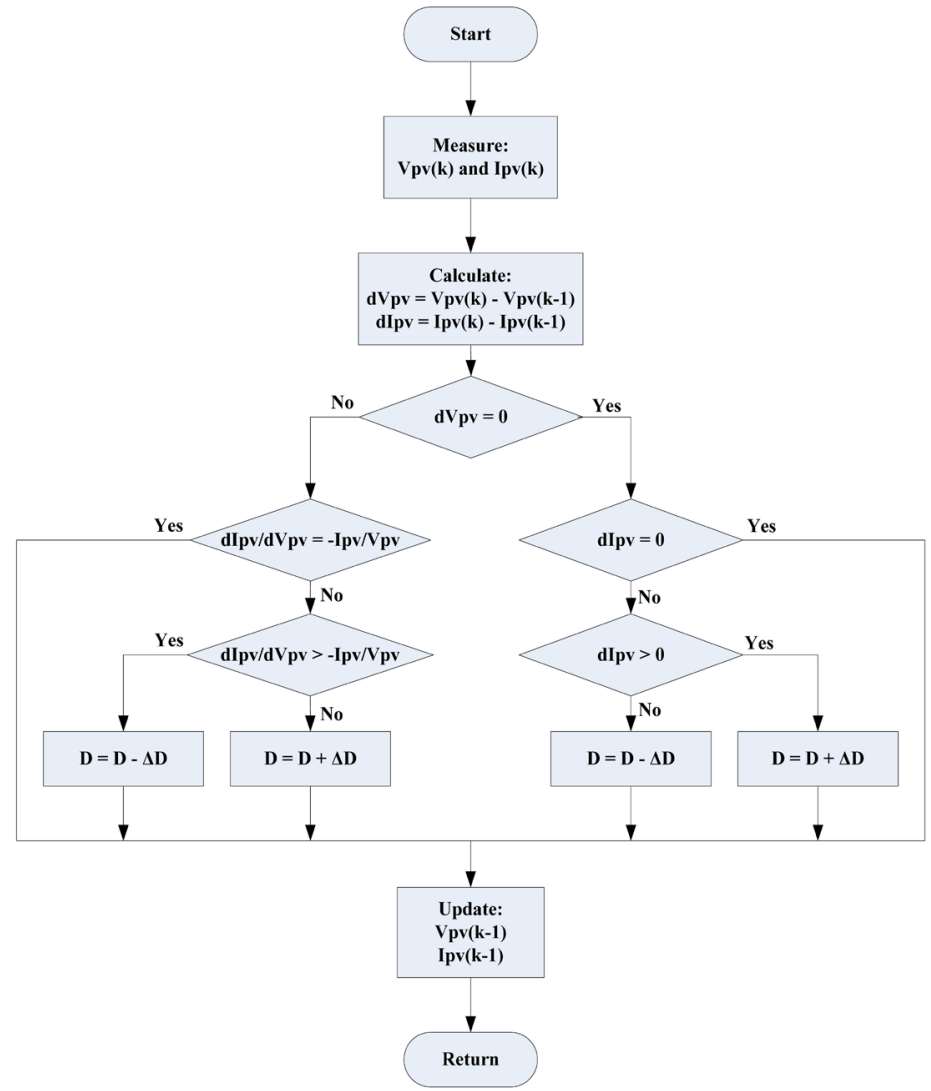

Figure 6. Flowchart of the INCF algorithm. 


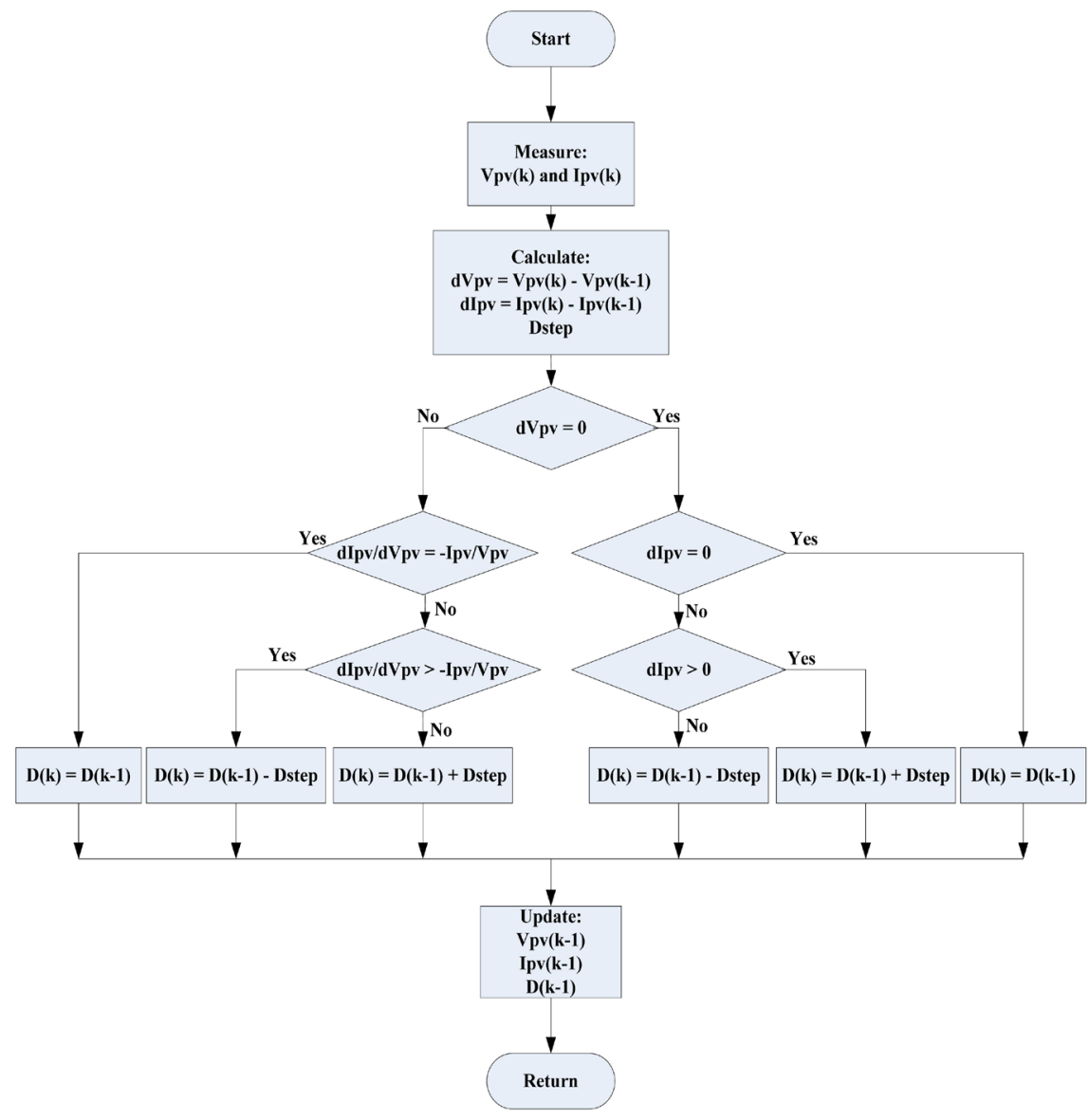

Figure 7. Flowchart of the INCV algorithm.

$$
\begin{gathered}
D_{\text {step }}=N\left|\frac{P_{p v}(k)-P_{p v}(k-1)}{V_{p v}(k)-V_{p v}(k-1)}\right| \\
N<\frac{D_{\text {stepmax }}}{\left|\frac{\mathrm{d} P_{p v}}{\mathrm{~d} V_{p v}}\right|_{\text {fixed step }=D_{\text {stepmax }}}}
\end{gathered}
$$

Jae-Hoon and Won-Pyo developed in 2013 [10] another expression of the step given in Equation (7). $N_{p}$, a and $c$ are constants which value values are determined according to the convergence condition of the system.

$$
D_{\text {step }}=N_{p}\left|1-\frac{1}{1+\exp \left[-a\left(\Delta P_{p v}-c\right)\right]}\right|
$$

\section{3) Modelling of the PV system}

The electrical model of a PV panel is widely known. In this research paper, the single-diode model is used because the experimental data were recorded on a monocrystalline silicon PV panel. The equivalent circuit of this panel is given by Dandoussou et al., 2015 [4]. The whole model of the PV system is given in Figure 8 below. There are four different blocks (or subsystems): 


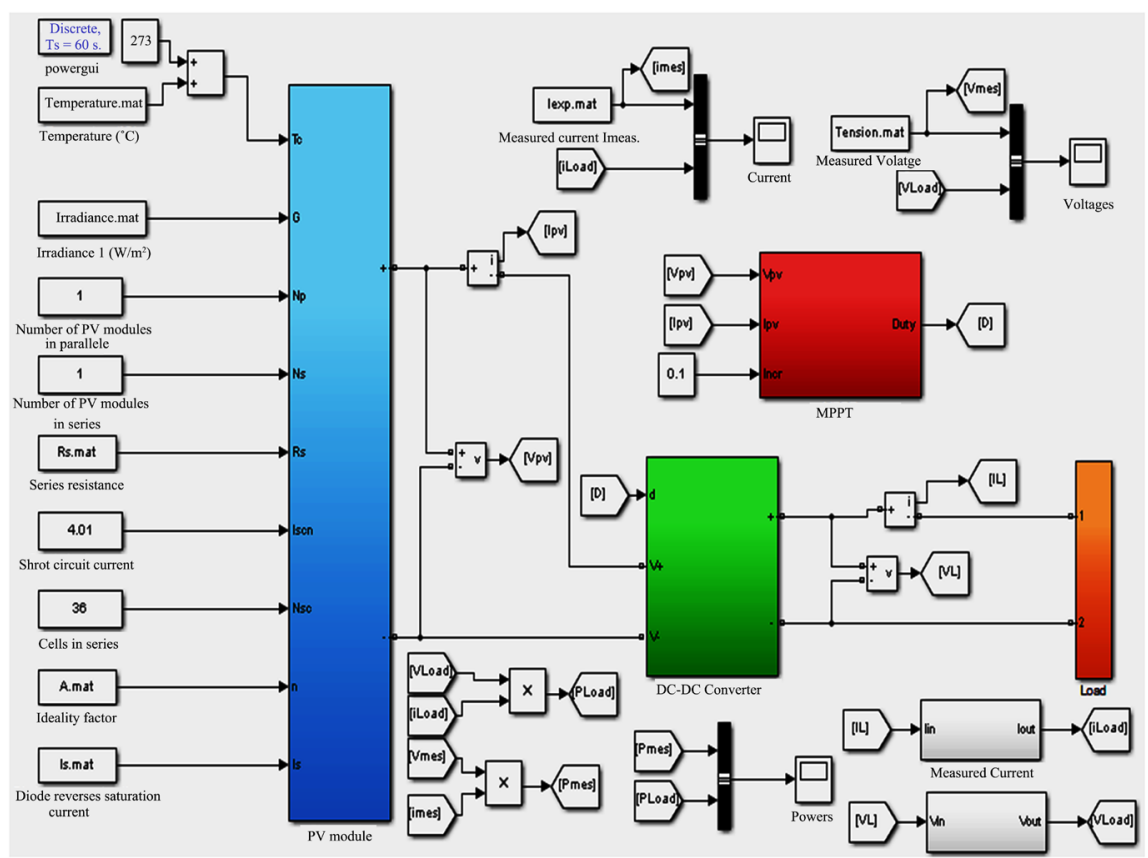

Figure 8. Simulink model of the PV system.

$\checkmark$ The first block is the PV panel having nine input variables. The surface temperature was recorded during one day as shown in Figure 9(a). The irradiance is also represented in Figure 9(a). These weather conditions were recorded on the 23rd of January 2013 in Ngaoundere, Cameroon (Latitude $7.3^{\circ} \mathrm{N}$ and Longitude $13.3^{\circ} \mathrm{E}$ ). The ideality factor, the series resistance and the reverse saturation current (see Figures 9(b)-(d) respectively) were extracted by Dandoussou et al., 2015 [4].

$\checkmark$ The second block is the DC-DC converter. Each of the two topologies (boost and buck converters) has been implemented.

$\checkmark$ The third block is the MPPT block. Using Stateflow under Simulink ${ }^{\otimes}$, the four MPPT algorithms (HC, P \& O, INCF and INCV) have been implemented.

$\checkmark$ The fourth block is the load block which is a rheostat of $7.5 \Omega$.

\section{Results}

\subsection{Hill Climbing (HC) Algorithm}

Figure 10 shows the output powers produced by the PV system according to the design parameters of the buck converter, using $\mathrm{HC}$ algorithm. The waveform in red (PoutHVBuck1) is obtained when $\mathrm{L}=935 \mu \mathrm{H}$ and $\mathrm{C}=2.67 \mu \mathrm{F}$, and the blue waveform (PoutHVBuck2) is obtained when $\mathrm{L}=935 \mu \mathrm{H}$ and $\mathrm{C}=26.7 \mu \mathrm{H}$. This means that during the design process of the buck converter with $\mathrm{HC}$ algorithm control method, it is important to focus on the values of the components so that it will avoid unstable output power.

Figure 11 shows the waveforms of the output powers of the PV system, using $\mathrm{HC}$ algorithm, according to the design parameters of the boost converter. The 


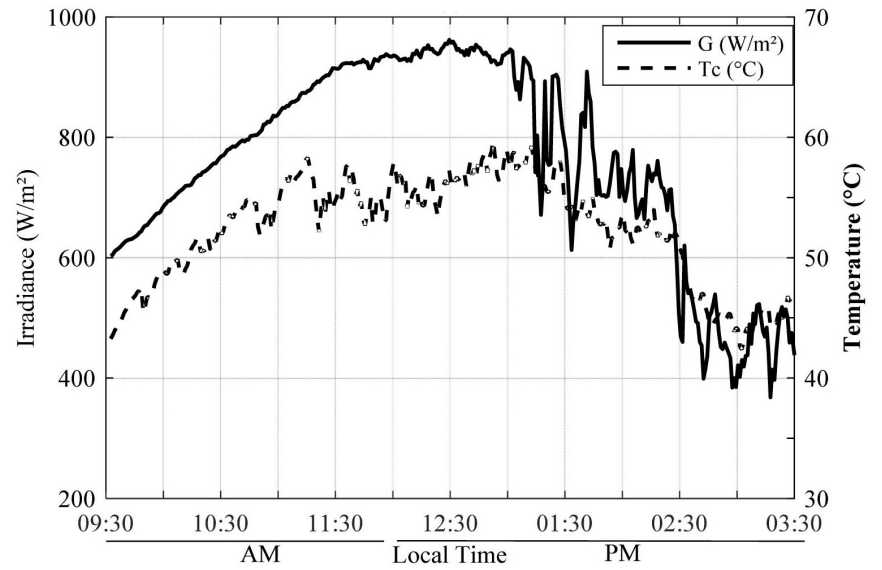

(a)

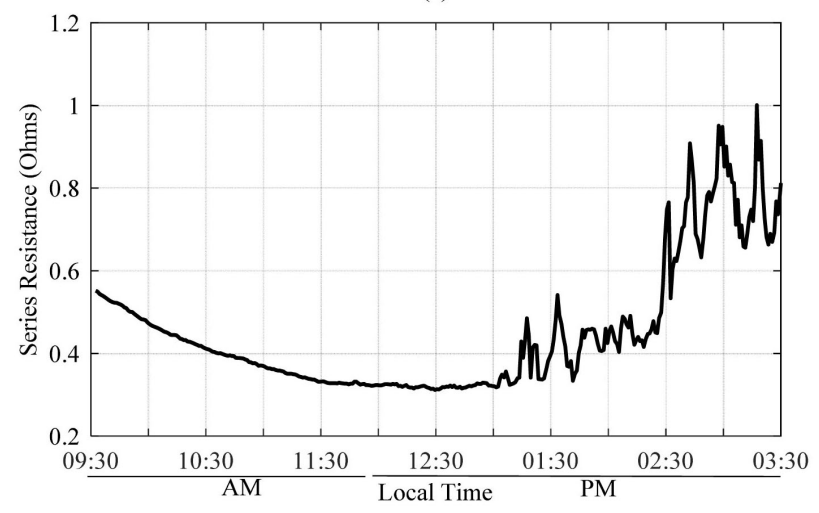

(c)

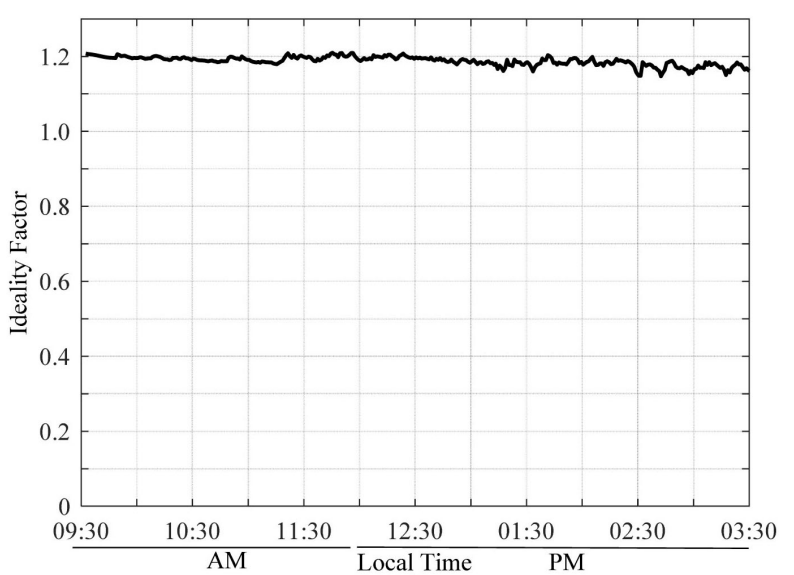

(b)

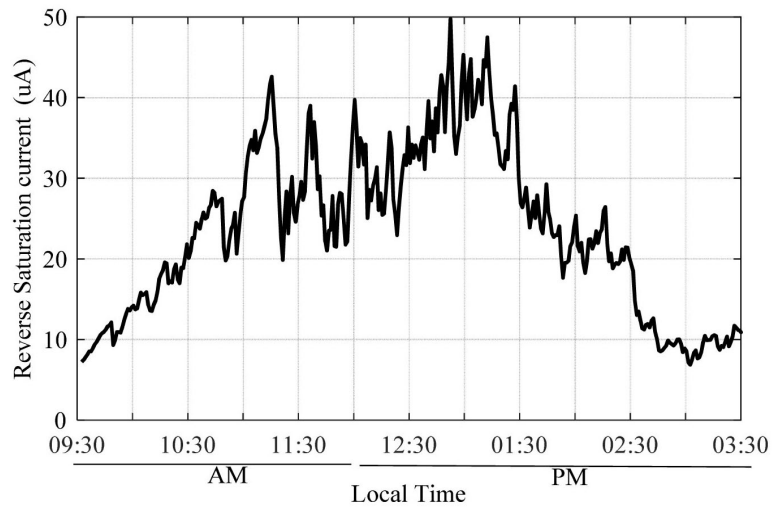

(d)

Figure 9. Input parameters of the PV system [4].

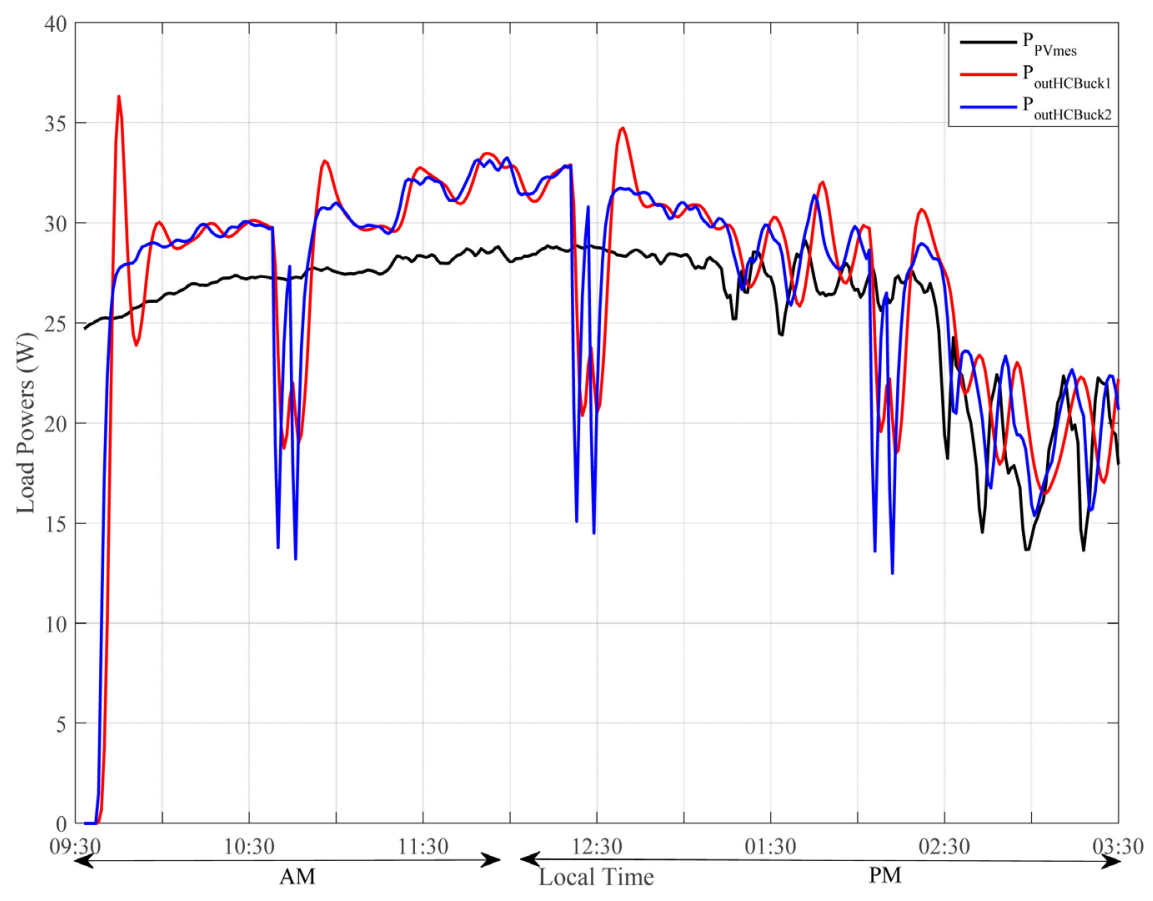

Figure 10. Output powers for HC algorithm according to the design of the buck converter. 


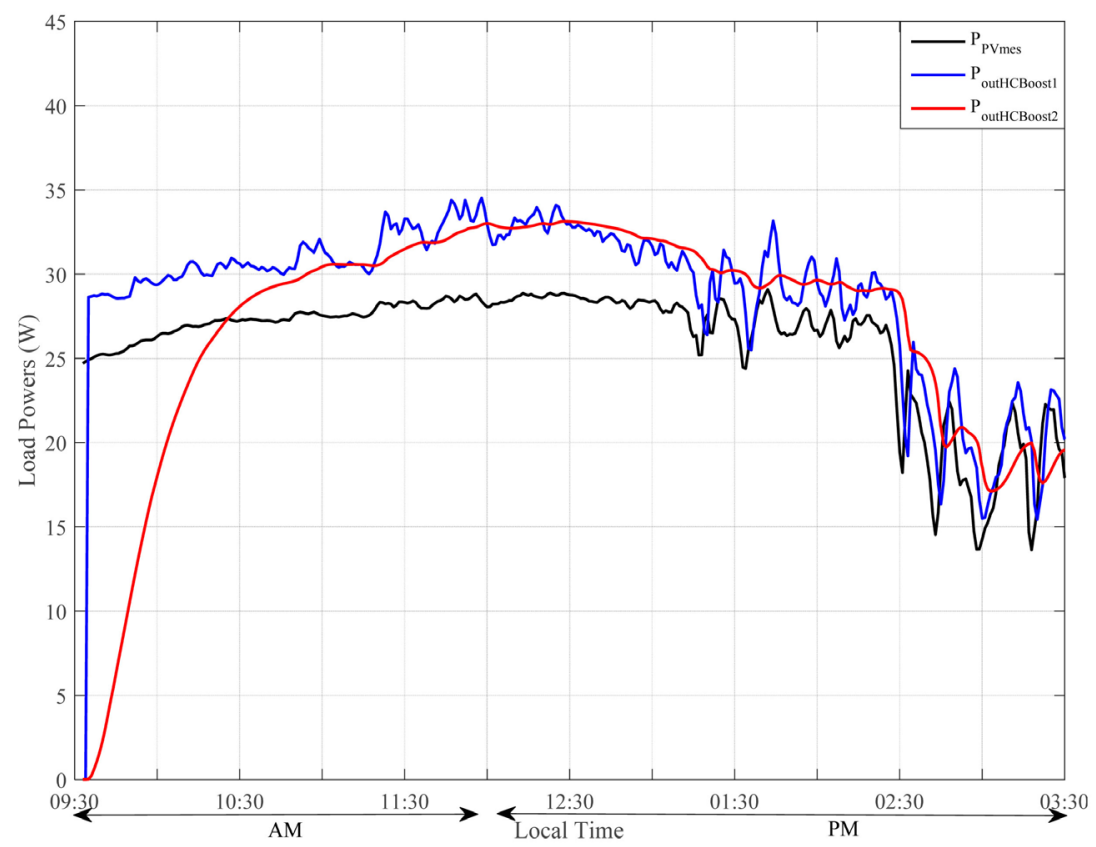

Figure 11. Output powers for $\mathrm{HC}$ algorithm according to the design of the boost converter.

red waveform (PoutHVBoost2) is for $\mathrm{L}=9350 \mu \mathrm{H}$ and $\mathrm{C}=2.67 \mu \mathrm{F}$ and the blue waveform is for $\mathrm{L}=935 \mu \mathrm{H}$ and $\mathrm{C}=2.67 \mu \mathrm{H}$. It's clear that when increasing the value of the inductance (L), even though the output power becomes more stable, the response time of the algorithm becomes too high. For a very small value of the inductance $(\mathrm{L})$, the output power becomes very unstable.

\subsection{Perturb and Observe (P \& 0) and Fixed Step Increment of Conductance (INCF) Algorithms}

Figure 12 shows the waveforms of the output powers produced by the PV system using P \& O or INCF algorithm, according to the design parameters of the buck converter. The red waveform (PoutINCFBuck1) is for $\mathrm{L}=935 \mu \mathrm{H}$ and $\mathrm{C}=$ $2.67 \mu \mathrm{F}$ and the blue waveform (PoutINCFBuck2) is for $\mathrm{L}=935 \mu \mathrm{H}$ and $\mathrm{C}=267$ $\mu \mathrm{F}$. It's clear that the value of the capacitor (C) affects the performance of the algorithm. When $\mathrm{C}$ is small, the output power is oscillating, with a small response time of the algorithm. When $\mathrm{C}$ is increasing, the output power becomes slightly stable, but the response time of the algorithm is high.

Figure 13 shows the output powers produced by the PV system using P \& O or INCF algorithm, according to the design parameters of the boost converter. The red waveform (PoutINCFBoost2) is for $\mathrm{L}=935 \mu \mathrm{H}$ and $\mathrm{C}=2.67 \mu \mathrm{F}$ and the blue waveform (PoutINCFBoost1) is for $\mathrm{L}=9350 \mu \mathrm{H}$ and $\mathrm{C}=2.67 \mu \mathrm{F}$. For the boost converter, it is the value of the inductance $(\mathrm{L})$ that affects the performance of the $\mathrm{P} \& \mathrm{O}$ or INCF algorithm. When $\mathrm{L}$ is small, the output power is stable, following normally the fluctuation of the weather conditions ( $G$ and $T$ ). When $L$ is increasing, the output power is more stable, but the response time of the algorithm is high. This leads to power losses. 


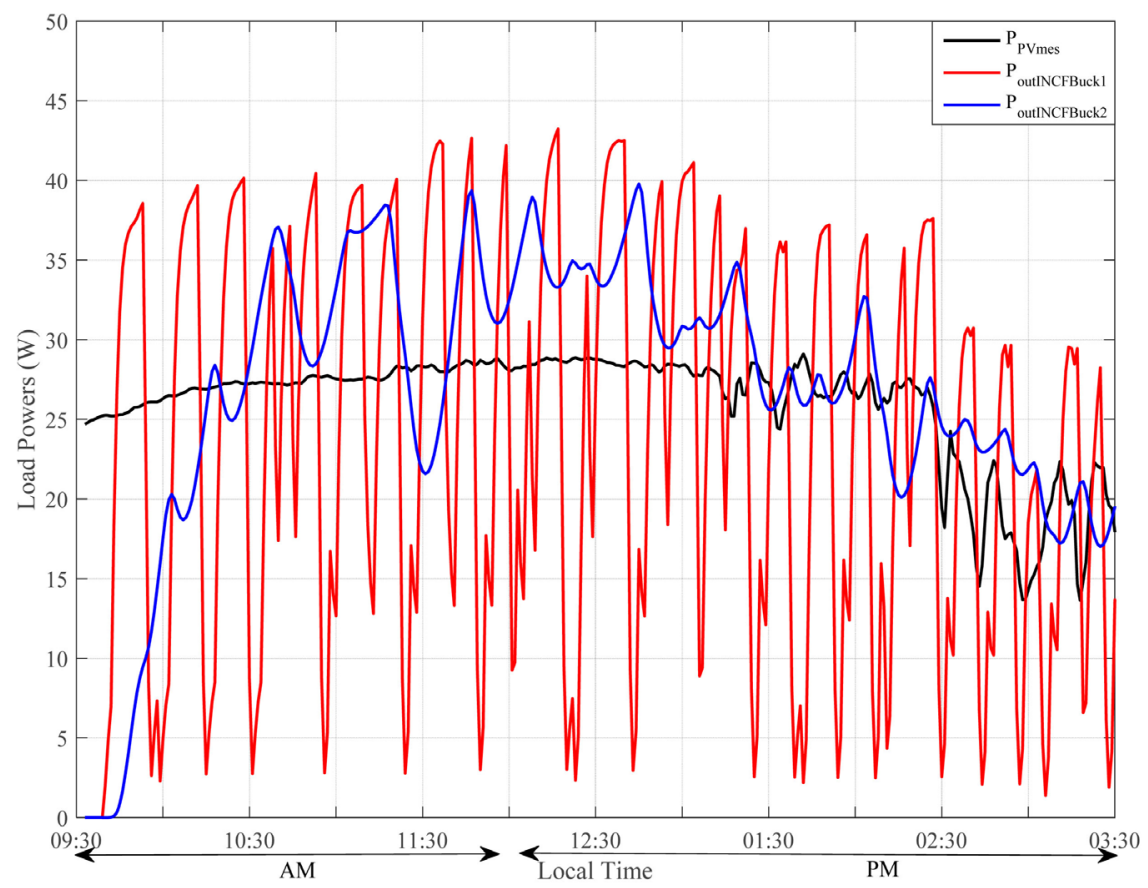

Figure 12. Output powers for INCF algorithm according to the design of the buck converter.

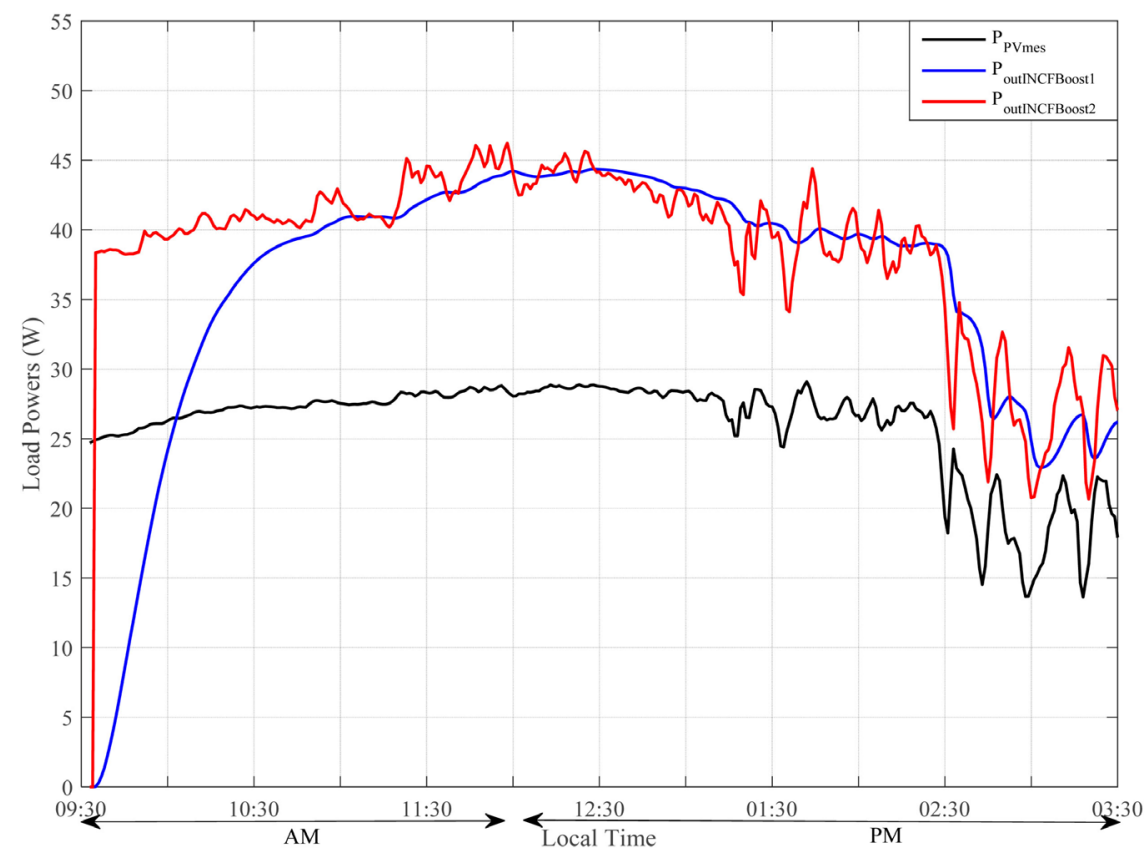

Figure 13. Output powers for INCF algorithm according to the design of the boost converter.

\subsection{Variable Step Increment of Conductance Algorithm (INCV)}

Figure 14 shows the waveforms of the output powers of the PV system using INCV algorithm, according to the design parameters of the buck converter. The red waveform (PoutINCVBuck1) is for $\mathrm{L}=935 \mu \mathrm{H}$ and $\mathrm{C}=2.67 \mu \mathrm{F}$, and the blue 


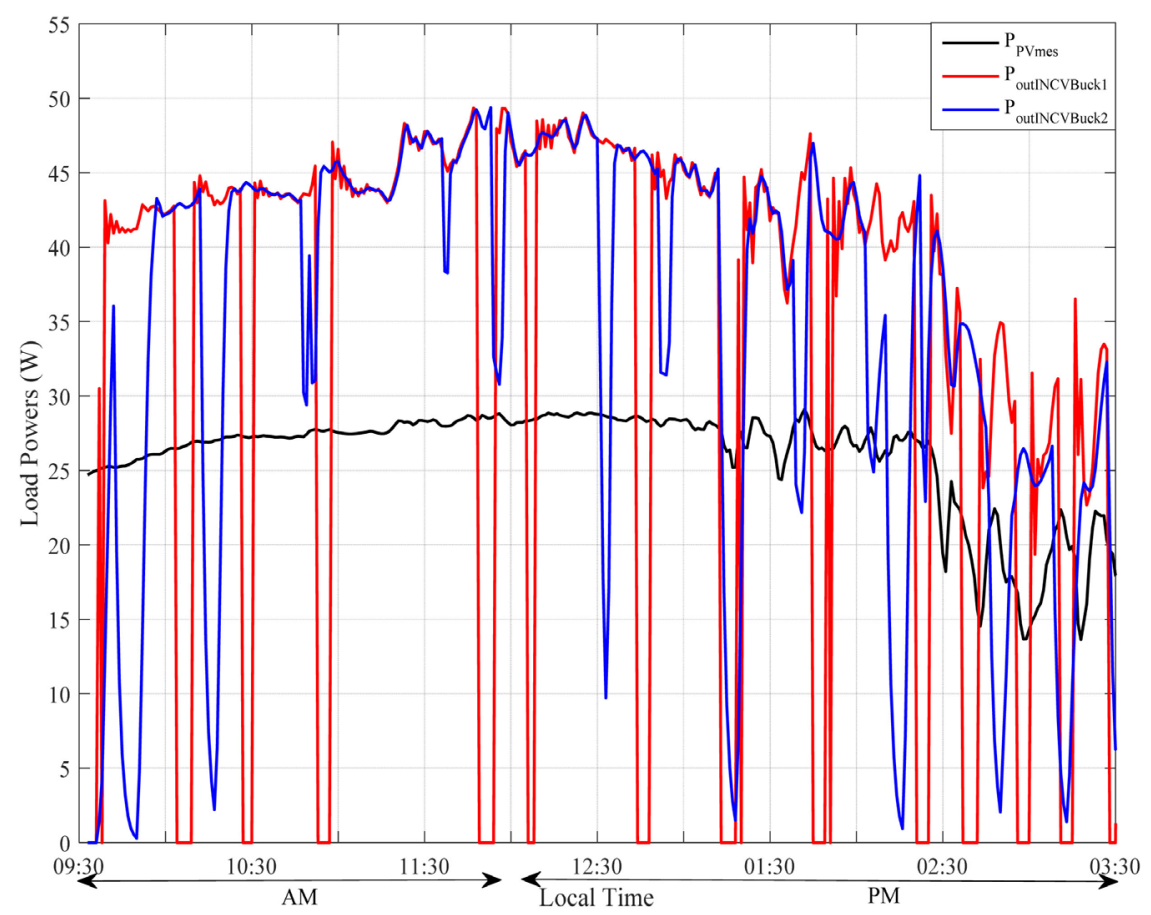

Figure 14. Output powers for INCV algorithm according to the design of the buck converter.

waveform (PoutINCVBuck2) is for $\mathrm{L}=935 \mu \mathrm{H}$ and $\mathrm{C}=26.7 \mu \mathrm{F}$. This means that the value of the capacitor (C) affects the performance of the INCV algorithm, controlling a buck converter. When $\mathrm{C}$ is small, the output power is unstable. When $\mathrm{C}$ is increasing, the output power is still oscillating, with power losses decreasing. The response time is not affected.

Figure 15 shows the output powers of the PV system using INCV algorithm, according to the design parameters of the boost converter. The red waveform (PoutINCVBoost2) is for $\mathrm{L}=935 \mu \mathrm{H}$ and $\mathrm{C}=2.67 \mu \mathrm{F}$, and the blue waveform (PoutINCVBoost1) is for $\mathrm{L}=9350 \mu \mathrm{H}$ and $\mathrm{C}=2.67 \mu \mathrm{F}$. Therefore, the value of the inductance $(\mathrm{L})$ affects the stability of the algorithm only when the system has been put on. This means that there are power losses only at the beginning when the value of $L$ is decreasing.

\section{Discussion}

Figure 16 shows the output powers obtained from the simulations, compared to the measured power on the direct-connected PV system (without MPPT block). As shown, it is clear that the HC algorithm has slightly increased the output power. However, the boost DC-DC converter is more efficient than the buck DC-DC converter. In fact, the buck converter loses energy at some moments of the day even if there is no fluctuation of the weather conditions (irradiance and temperature).

The simulated results for these two algorithms are shown in Figure 17. It should be recalled that these two algorithms have the same performance as 


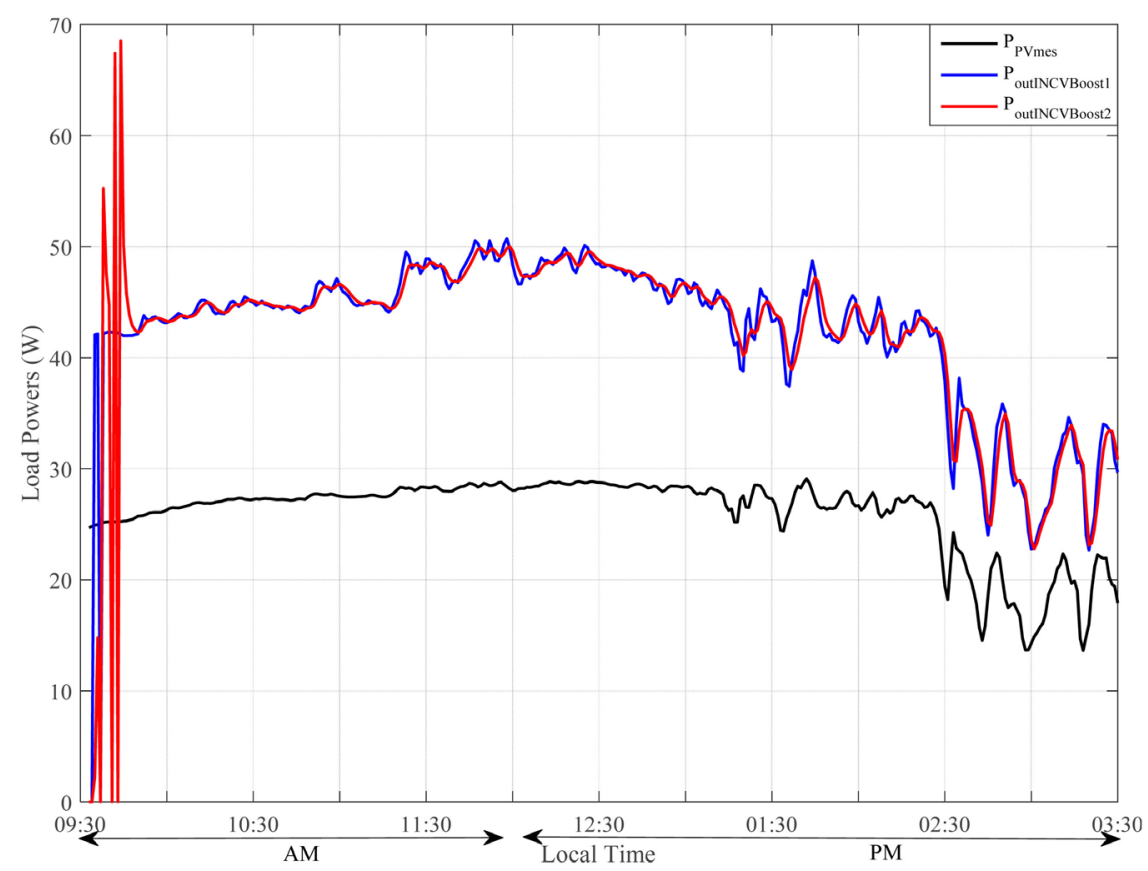

Figure 15. Output powers for INCV algorithm according to the design of the boost converter.

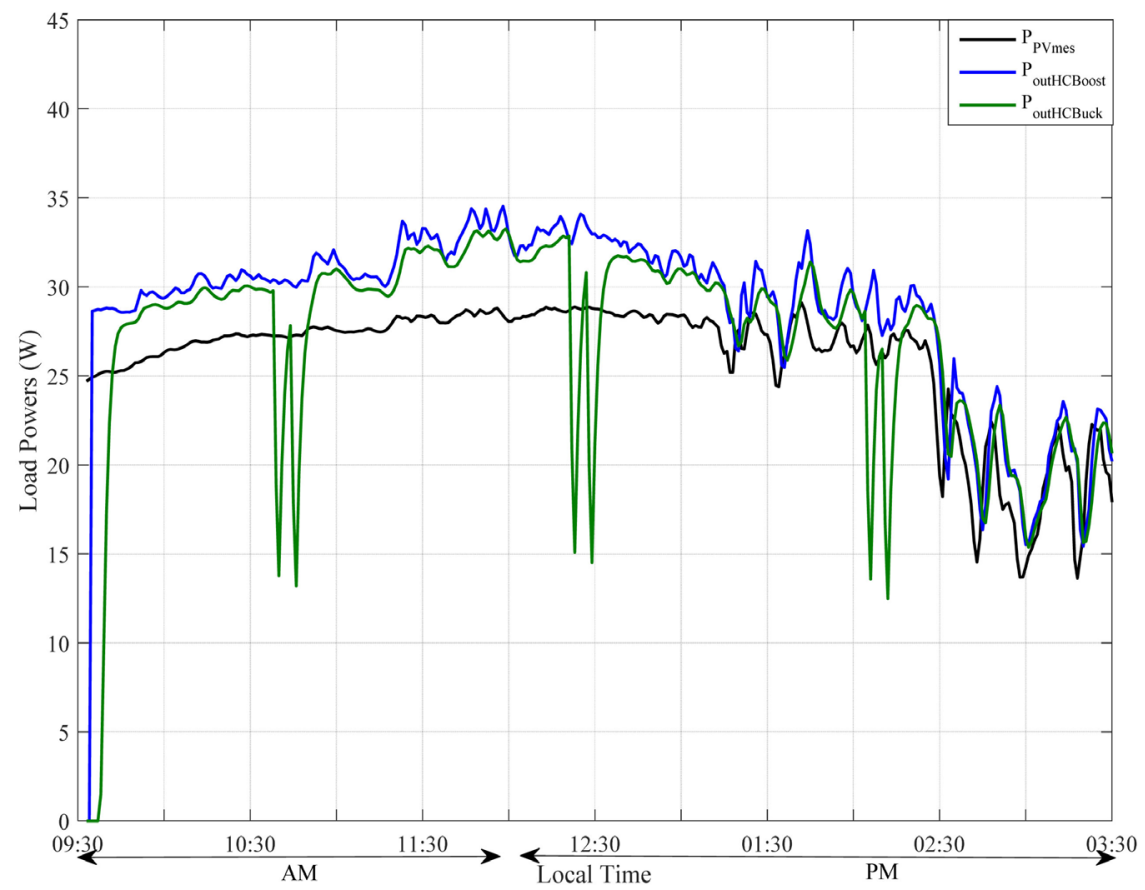

Figure 16. Comparison between the two converters with $\mathrm{HC}$ algorithm.

proved by Dandoussou et al., 2017 [5]. With these two algorithms, the buck converter produces power that is fluctuating during the whole day. This means that power losses are high compare to the boost converter.

The output powers are shown in Figure 18. Known as the best, compare to the first three algorithms (HC, P \& O and INCF), the INCV algorithm is no 


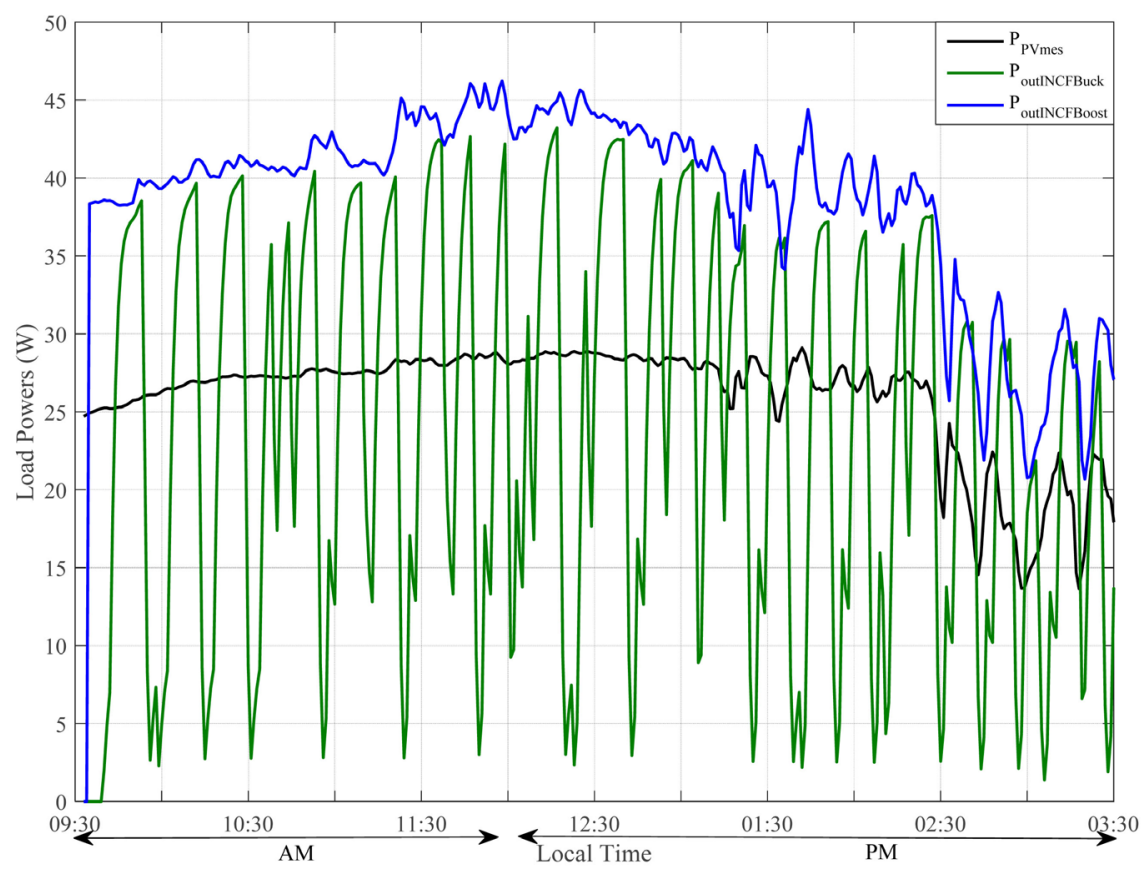

Figure 17. Comparison between the two converters with INCF algorithm.

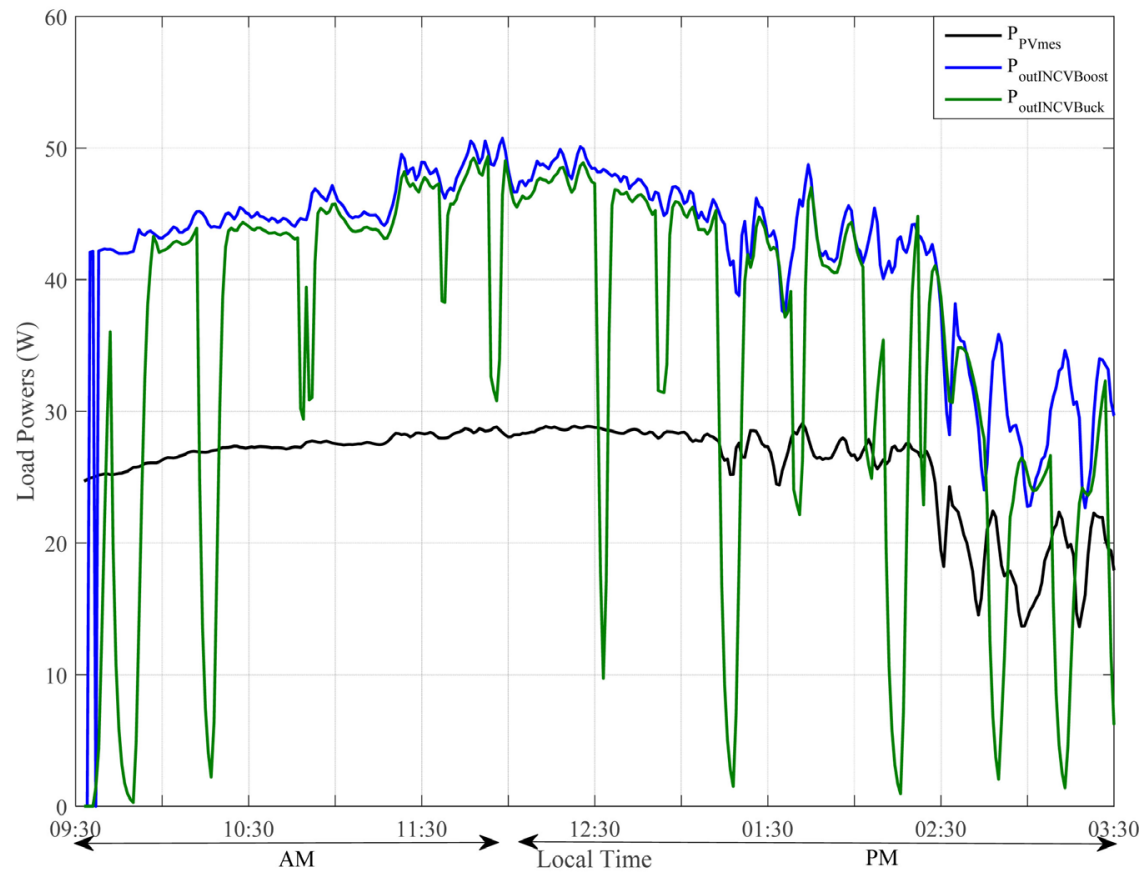

Figure 18. Comparison between the two converters with INCV algorithm.

more suitable for the buck converter. There are power losses during the whole day.

Table 3 shows the calculated energy produced by each MPPT algorithm with respect to the DC-DC converter topology. This energy was calculated from Equation (8) using Matlab command: $E=\operatorname{trapz}(t, P$ ), with $t$ the time (from 10:00 to 15:30) and $P$ the produced power (in $\mathrm{W}$ ). The measured energy is given by Emes $=$ 
Table 3. The daily energy produced each MPPT algorithm.

\begin{tabular}{cccc}
\hline & $\mathrm{E}_{\mathrm{HC}}(\mathrm{Wh})$ & $\mathrm{E}_{\mathrm{P} \& \mathrm{O}, \mathrm{INCF}}(\mathrm{Wh})$ & $\mathrm{E}_{\mathrm{INCV}}(\mathrm{Wh})$ \\
\hline Buck Converter & 170.65 & 140.13 & 209.37 \\
Boost Converter & 179.31 & 240.12 & 262.80 \\
\hline
\end{tabular}

160.93 Wh. With the buck converter controlled by P \& O or INCF algorithm, the output energy is low compare to the measured energy on the system without MPPT. Once more the INCV algorithm has the best performance whatever which converter is used.

$$
\mathrm{d} E=P \mathrm{~d} t \Rightarrow E=\int_{t_{0}}^{t_{1}} P \mathrm{~d} t
$$

\section{Conclusion}

This paper focused on the simulations of MPPT algorithms according to two topologies of DC-DC converters. Recorded temperature and irradiance and extracted PV parameters (ideality factor, series resistance and reverse saturation current) were used to simulate the PV systems using Matlab/Simulink'. From the obtained results, it is clear that there are some power losses during the whole day, independent from the weather conditions, when the buck converter is used. The output powers fluctuate during the whole day. The boost converter is suitable for all the MPPT algorithms, with the INCV algorithms having the best performance. However, in further works, it would be better to take into consideration others factors like the PV technologies, the other DC-DC converter topologies, additional electronics circuits (a stabiliser for example).

\section{Acknowledgements}

Authors thank the Director of HTTTC Kumba for providing some key equipment for this research work to be realized smoothly.

\section{Conflicts of Interest}

The authors declare no conflicts of interest regarding the publication of this paper.

\section{References}

[1] Abdulkadir, M., Samosir, A.S., Yatim, A.H.M. and Yusuf, S.T. (2013) A New Approach of Modelling, Simulation of MPPT for Photovoltaic System in Simulink Model. ARPN Journal of Engineering and Applied Sciences, 8, 488-494.

[2] Alsadi, S. and Alsayid, B. (2012) Maximum Power Point Tracking Simulation for Photovoltaic Systems Using Perturb and Observe Algorithm. International Journal of Engineering and Innovative Technology, 2, 80.

[3] Brito, M.A.G., Galotto, L., Sampaio, L.P., de Azevedo e Melo, G. and Canesin, C.A. (2013) Evaluation of the Main MPPT Techniques for Photovoltaic Applications. IEEE Transactions on Industrial Electronics, 60, 1156-1167. https://doi.org/10.1109/TIE.2012.2198036 
[4] Dandoussou, A., Kamta, M., Bitjoka, L., Wira, P. and Kuitché, A. (2015) Simulations Based on Experimental Data of the Behaviour of a Monocrystalline Silicon Photovoltaic Module. Journal of Solar Energy, 2015, Article ID: 169015. https://doi.org/10.1155/2015/169015

[5] Dandoussou, A., Kamta, M., Bitjoka, L., Wira, P. and Kuitché, A. (2017) Comparative Study of the Reliability of MPPT Algorithms for Crystalline Silicon Photovoltaic Module in Variable Weather Conditions. Journal of Electrical Systems and Information Technology, 4, 213-224. https://doi.org/10.1016/j.jesit.2016.08.008

[6] Durusu, A., Nakir, I., Ajder, A., Ayaz, R., Akca, H. and Tanrioven, M. (2014) Performance Comparison of Widely-Used Maximum Power Point Tracker Algorithms under Real Environmental Conditions. Advances in Electrical and Computer Engineering, 14, 89-94. https://doi.org/10.4316/AECE.2014.03011

[7] Hohm, D.P. and Ropp, M.E. (2000) Comparative Study of Maximum Power Point Tracking Algorithm Using an Experimental Programmable Maximum Power Point Tracking Test Bed. IEEE Photovoltaic Specialists Conference, Anchorage, 15-22 September 2000, 1699-1702.

[8] Hussein, K.H., Muta, I., Hoshino, T. and Osakada, M. (1995) Maximum Photovoltaic Power Tracking: An Algorithm for Rapidly Changing Atmospheric Conditions. IEEE Proceedings Transmission and Distribution, 142, 59-64. https://doi.org/10.1049/ip-gtd:19951577

[9] Irisawa, K., Saito, T., Takano, I. and Sawada, Y. (2000) Maximum Power Point Tracking Control of Photovoltaic Generation System under Non-Uniform Insolation by Means of Monitoring Cells. IEEE Photovoltaic Specialists Conference, 20 th, Las Vegas, 26-30 September 1988, 1707-1710.

[10] Jae-Hoon, C. and Won-Pyo, H. (2013) A Variable Step Size Incremental Conductance MPPT of a Photovoltaic System Using DC-DC Converter with Direct Control Scheme. Journal of the Korean Institute of Illuminating and Electrical Installation Engineers, 27, 74-82. https://doi.org/10.5207/JIEIE.2013.27.9.074

[11] Kumar, Ch.K., Dinesh, T. and Babu, S.G. (2013) Design and Modelling of PV System and Different MPPT Algorithms. International Journal of Engineering Trends and Technology, 4, 4104-4112.

[12] Liu, F., Duan, S., Liu, F., Liu, B. and Kang, Y. (2008) A Variable Step Size INC MPPT Method for PV Systems. IEEE Transactions on Industrial Electronics, 55, 2622-2628. https://doi.org/10.1109/TIE.2008.920550

[13] Lokanadham, M. and Vijaya, K.B. (2012) Incremental Conductance Based Maximum Power Point Tracking (MPPT) for Photovoltaic System. International Journal of Engineering Research and Applications, 2, 1420-1424.

[14] Rathod, G., Gorawar, M., Revankar, P.P. and Tewari, P.G. (2014) Matlab Based Comparative Studies on Selected MPPT Algorithms for SPS System. IJRET: International Journal of Research in Engineering and Technology, 3, 7. https://doi.org/10.15623/ijret.2014.0307002

[15] Sahu, T.P., Dixit, T.V. and Kumar, R. (2014) Simulation and Analysis of Perturb and Observe MPPT Algorithm for PV Array Using CUK Converter. Advance in Electronic and Electric Engineering, 4, 213-224.

[16] Yatimi, H. and Aroudam, E. (2018) MPPT Algorithms Based Modeling and Control for Photovoltaic System under Variable Climatic Conditions. Procedia Manufacturing, 22, 757-764. https://doi.org/10.1016/j.promfg.2018.03.108

[17] Soulatiantork, P. (2020) Experimental Performance Evaluation of P \& O and IC MPPT Algorithms for Photovoltaic Systems under Constant and Variable Envi- 
ronmental Conditions. International Journal of Energy Engineering, 10, 46-58.

[18] Lee, H.-S. and Yin, J.-J. (2019) Advanced MPPT Algorithm for Distributed PV Systems. Energies, 12, 3576. https://doi.org/10.3390/en12183576

[19] Nguyen, B.N., Nguyen, V.T., Duong, M.Q., Le, K.H., Nguyen, H.H. and Doan, A.T. (2020) Propose a MPPT Algorithm Based on Thevenin Equivalent Circuit for Improving Photovoltaic System Operation. Frontiers in Energy Research, 8, 14. https://doi.org/10.3389/fenrg.2020.00014

[20] Motahhir, S., Hammoumi, A.E. and Ghzizal, A. (2020) The Most Used MPPT Algorithms: Review and the Suitable Low-Cost Embedded Board for Each Algorithm. Journal of Cleaner Production, 246, Article ID: 118983. https://doi.org/10.1016/j.jclepro.2019.118983

[21] Saravana, S.D. (2013) Modeling and Simulation of Incremental Conductance MPPT Algorithm for Photovoltaic Applications. International Journal of Scientific Engineering and Technology, 2, 681-685.

[22] Saxena, A.R. and Gupta, S.M. (2014) Performance Analysis of P \& O and Incremental Conductance MPPT Algorithms under Rapidly Changing Weather Conditions. Journal of Electrical Systems, 10, 292-304.

[23] Sera, D., Kerekes, T., Teodorescu, R. and Blaadjerg, F. (2006) Improved MPPT Algorithms for Rapidly Changing Environment Conditions. Power Electronics and Motion Control Conference, EPE-PEMC 2006, 12 th International, Portorož, 30 August-1 September 2006, 1614-1619. https://doi.org/10.1016/j.jclepro.2019.118983

[24] Srdic, S., Radakovic, Z. and Vojinovic, V. (2012) Implementation of the Incremental Conductance MPPT Algorithm for Photovoltaic Systems. IX Symposium Industrial Electronics INDEL 2012, Banja Luka, 1-3 November 2012, 11 p.

[25] Teulings, W.J.A., Marpinard, J.C., Capel, A. and O’Sullivan, D. (1993) A New Maximum Power Point Tracking System. IEEE Power Electronics Specialists Conference, Seattle, 20-24 June 1993, 833-838.

[26] Tey, K.S. and Mekhilef, S. (2014) Modified Incremental Conductance MPPT Algorithm to Mitigate Inaccurate Responses under Fast-Changing Solar Irradiation Level. Solar Energy, 101, 333-342. https://doi.org/10.1016/j.solener.2014.01.003

[27] Tse, K.K., Ho, M.T., Chung, H.S. and Ron Hui, S.Y. (2004) A Comparative Study of Maximum Power Point Trackers for Photovoltaic Panels Using Switching-Frequency Modulation Scheme. IEEE Transaction on Industrial Electronics, 51, 410-418. https://doi.org/10.1109/TIE.2004.825226

[28] Xiao, W. and Dunford, W.G. (2004) A Modified Adaptive Hill Climbing MPPT Method for Photovoltaic Power Systems. Industrial Electronics Specialists Conference, PESC04, Vol. 3, 2883-2887. 